\title{
Improving the Efficiency of Fuel Usage in New Coal Technologies
}

\author{
Pavel Shchinnikov, Gennadiy Nozdrenko, Oksana Grigorieva, \\ Anna Galanova (Corresponding author), Anton Safronov, Alina Franceva \& Valentina Muhina \\ Department of Thermal Power Plant, Novosibirsk State Technical University \\ 630092, Prospect Marksa, 20, Novosibirsk, Russia
}

Tel: 7-383-346-1142Ｅ-mail: tes.nstu@gmail.com

Received: October 18, 2011

Accepted: November 8, 2011 Published: December 31, 2011

doi:10.5539/mer.v1n1p79

URL: http://dx.doi.org/10.5539/mer.v1n1p79

\begin{abstract}
The increase of the fuel usage efficiency by application of new coal technologies, modern automation and control meanings were considered in the paper. The results of comprehensive researches of promising coal technology efficiency are given. It is shown that their efficiency is 1,15-1,7 times higher than conventional coal unit one. The parameters deviation influences on fuel overexpenditure at unsteady state were researched. It provides exact cause-and-effect relation between automation means and fuel expenditure of thermal power plant. Unit operation on boiler stored energy at emergency is researched. It is shown that the automation reduces significantly recovery time of unit normal load thereby it reduce the damage caused by emergency. Besides there were shown the effect of power generating equipment on environment, social infrastructure and health care. There are given reasonable ratio between infrastructure and health care costs that occur in a big city where thermal power plant was installed.
\end{abstract}

Keywords: Efficiency, Composite liquid coal fuel, Freon compressor heat pump, Automatic control system, Emergency, Boiler stored energy, Balance matching method, Pollutant emissions

\section{Introduction}

The efficiency of fuel usage on thermal power plant (TPP) may be improved by new technologies application, such as supercritical one, combined-cycle gas turbine with gas delivery heater (GDH), cavity fuel with the production of composite liquid coal fuel (CLCF) and heat pump, working in a combined heating system with Freon compressor heat pumps. Comprehensive researches of promising coal technology are urgent nowadays. They allow comparing different schemes and show effectiveness of their implementation in different cases. In section 2 the results of such researches are given.

On the other hand the efficiency of fuel usage may be improved by modern automation and control means. It is necessary to find relations between live steam parameters deviations and fuel expenditure to impartial comparing of automation means among themselves. These relations are shown in the section 3. Besides, modern control automation at emergency are described there. Unit operation on boiler stored energy at emergency is researched. As a result of researches some advices about implementation of such control automation are given.

The problem of pollutant emissions reduction from TPP is urgent nowadays. The effect of power generating equipment on environment, social infrastructure and health care is researched in section 4 . There are given reasonable ratio between infrastructure and health care costs that occur in a big city where thermal power plant was installed.

\section{Improving the Efficiency of Fuel Usage in Power Engineering}

For competitive recovery of coal as a strategic fuel it is necessary to increase fuel efficiency. This is achieved by the application of new power energy technologies, such as supercritical (supercritical parameter - SCP, Fig. 1) with pressure and temperature of superheated steam at the outlet from the boiler to reach $30 \mathrm{MPa} / 600^{\circ} \mathrm{C} / 600^{\circ} \mathrm{C}$, combined-cycle gas turbine (Fig. 2) with GDH, working in a mode of hot water, cavity fuel (Fig. 3) with the production of CLCF (Tomilov et al., Patent for invention №2151959 \& №2151170, 2000), heat pump (Fig. 4), working in a combined heating system with Freon compressor heat pumps.

The calculations were done by the software developed in Novosibirsk State Technical University and computer systems (Nozdrenko \& Shchinnikov, 2009). 
For given initial and final supercritical steam parameters, the parameters of reheat, feedwater heating scheme is calculated. By functionally dependent parameters such as consumption of operating mediums, temperature differences, heat flows transmitted, the concentrations of pollutants, design-layout parameters of the components, weight and cost characteristics, various coefficients, etc.

Dependences between parameters are described by the equations of energy, consumables and hydraulic balance. The Balance equations in the components determine a relation between the thermodynamic parameters and consumables, which provides steady-state load power given to certain elements of the design parameters and technological parameters of the form (including heat) of the unit.

For each version of the current scheme of thermal power units run with a joint connection: heat and balance calculations the boiler, turbine, regenerative heaters, condenser, drive turbines, main pipelines, the technical systems (fuel, pulverizing, draft, water, ash handling, treatment and evacuation of combustion gases); to calculate the power of auxiliaries; determining the fuel consumptions.

In accordance with the contents of a complete system of settlement statements, other than those mentioned above shall include procedures for: determining the thermodynamic parameters of water and steam, sorting versions parameters, schema changes power. Computer system provides a fairly accurate description of real processes, both in the context of functioning parts, and communication linkages.

Models include the relationship between input and output flow-thermodynamic parameters, as well as the relationship between these parameters and structural characteristics of the elements, checking the parameters for all types of constraints, validation of the calculated values of the efficiency (non-negativity cost differential pressures, energy and material flows, etc.)

The investment includes the cost of creating, assembly, delivery of equipment to the construction, technical development, as well as the cost of the main building, site preparation, construction of temporary buildings, design work, part-time assignment objects. Fig. 5... fig. 8 show the values $\eta$ of efficiency units with the considered technologies.

\section{Improving the Efficiency of Fuel Usage Owing to Application of Modern Automation and Control Systems}

\subsection{Reduction of fuel expenditure at parameters deviation}

According to the regulatory requirements, if live steam pressure and temperature are maintained by automatic control systems (ACS), the maximal deviations of live steam pressure $p_{l . s}$ and temperature $t_{l . s}$ in steady modes of the power unit load must not exceed $\pm 1 \%$ and $\pm 5^{\circ} \mathrm{C}$, respectively. The control process itself is performed for each influencing parameter and is oscillatory by nature. The quality of control is determined from the extent of oscillation, control time, and integral quadratic criterion. The totality of these indicators characterizes how perfect the control system is, i.e., its ability to return the controlled parameter to its nominal value with the optimal dynamics and, hence, with the minimal overexpenditure of fuel. The perfectness of a system depends on the control laws laid down in it and on its technical implementation.

The specific expenditures of equivalent fuel $[\mathrm{kgce} /(\mathrm{kW} \mathrm{h})]$ for generation (supply) of heat and electricity by a cogeneration power unit (as the general case) are determined from the following expressions:

$$
b_{Q}=\frac{0.123}{\eta_{Q}} ; b_{N}=\frac{0.123}{\eta_{N}} ;
$$

where $\eta_{Q}$ and $\eta_{N}$ are the efficiencies for supply of heat and electricity.

The overexpenditures of equivalent fuel resulting from deviation of the parameter $x$ from its standardized value by $\Delta x$ (e.g., the initial values of steam flow rate, reheat steam temperature, etc.) can be calculated from the following formulas:

$$
\Delta b_{Q}=\sum_{n}\left(\frac{\partial b_{Q}}{\partial x_{n}}\right) \Delta x_{n} ; \Delta b_{N}=\sum_{n}\left(\frac{\partial b_{N}}{\partial x_{n}}\right) \Delta x_{n}
$$

where $\Delta b_{Q}, \Delta b_{\mathrm{N}}$ are the specific overexpenditures of fuel for supply of heat and electricity, and $n$ is the kind of deviated parameter. The summation symbol reflects the totality of all control parameters (Shchinnikov et al., 2009).

The integral overexpenditure of fuel for the time $t_{c n t r}$ during transients involving simultaneous deviations of controlled parameters is estimated from the following expressions: 


$$
\sum \Delta B_{Q} \approx \int_{0}^{t_{p e r}} \Delta B_{Q}(t) d t ; \sum \Delta B_{N} \approx \int_{0}^{t_{p e r}} \Delta B_{N}(t) d t
$$

where $\Delta B_{Q}, \Delta B_{\mathrm{N}}$ are the total overexpenditures of fuel for supplying heat and electricity during the time of returning to its nominal value of deviated parameters.

The resulting overexpenditure of fuel of the power unit for the control time

$$
\Delta B=\Delta B_{Q}+\Delta B_{N}
$$

and when it is expressed in relative units

$$
\delta b_{Q}=\frac{\Delta B_{Q}}{B_{Q}} 100 \% ; \delta b_{N}=\frac{\Delta B_{N}}{B_{N}} 100 \%
$$

where $B$ is the expenditure of fuel when the power unit operates without deviation of its parameters, and $\delta b_{Q}$ and $\delta b_{N}$ are the relative specific overexpenditures of fuel during generation of heat and electricity respectively.

These formulas were used to analyze how deviations of live steam temperature and pressure affect overexpenditure of fuel in cogeneration power units equipped with T-100 turbines. The influencing parameter was allowed to deviate by up to $5 \%$ of its nominal value.

The calculations were carried out using the ORTES software package (Nozdrenko \& Shchinnikov, 2009). The results of these calculations (Fig. 9) show that deviation of $p_{1 . s}$ is most significant, because it is exactly this parameter that makes larger contribution to overexpenditure of fuel. The contribution caused by deviations of live steam temperature is less noticeable.

The absolute overexpenditure of fuel (for the control time) in cogeneration units can be equal to $0.30-0.65$ $\mathrm{kgce} / \mathrm{s}$ for supply of heat and $0.30-0.55 \mathrm{kgce} / \mathrm{s}$ for supply of electricity, depending on the load. It should be noted that the maximal supply of heat is characterized by the minimal overexpenditure of fuel. As the load decreases by a factor of 2, the overexpenditure of fuel increases by a factor of 1.7-2.0 (Fig. 9) and the dependence is close to a linear one.

Thus, overexpenditures of fuel caused by deviations of live steam parameters from their nominal values must be estimated taking into account both pressure and temperature. Pressure should be taken into account due to thermodynamic features, and temperature, due to inertial nature of control processes. The relative overexpenditure of fuel for cogeneration power units is around $4-10 \%$ at loads close to nominal $(80-100 \%)$ and increases to $30 \%$ as the load decreases to $40 \%$.

\subsection{Use of boiler stored energy for auxiliary load supporting}

That is actual problem at emergencies, such as shutdown of generator. In this case auxiliary load supporting automation (ALSA) controls power unit and supports auxiliary load during some time required for recovery of normal generator state and reduction of unit load recovery time.

Reasonability of ALSA implementation is proved by the increase of serious blackout frequency and economic damage from the emergencies (Semenov, 2005). For example, Moscow blackout caused shutdown of 13 power plants and $3540 \mathrm{MW}$ consumers. Economic damage is estimated at 1.7 billion of rubles. ALSA reduces significantly recovery time of unit normal load thereby it reduce the damage caused by emergency. There are the most serious blackouts occurred in the world in table 1.The most difficult for ALSA implementation is power unit with coal burning drum boiler because quick balancing of steam and heat rates (on the basis of equipment technical features) for this type of boiler is impossible. Drum boilers have high specific ability to store the energy (in comparison with once-through boiler it is 2-3 times higher). Therefore coal flame in boiler furnace should be blown out and boiler stored energy should be used for auxiliary load supporting in deep unloading mode.

An algorithm of ALSA for power unit with drum boiler is shown in fig. 10. It was offered by Sibtechenergo company and implemented on 20 power units in Russia and other countries (Novikov et al., 1981).

Emergency is detected by special sensors. Technological protection system that controls water level in the boiler drum is used for boiler shutdown. Analysis of the algorithm shows simplicity of its implementation, its reliability and exclusion of large quantity of operations in comparison with alternatives.

Possibility of mentioned protection system usage is usually checked by experiments. Method of drum level changing calculation is described below and valid in case of dramatic pressure increase in water-steam circuit. 
Dependence of water level from water volume in the drum is shown for different steam capacity boiler in fig. 11. Then steam volume fraction in the furnace tubes $x$ is estimated using the simplified Dolezal's method of circulation calculation (Dolezal, 1971).The decrease of steam volume in the furnace tubes water at dramatic pressure increase is taken equal to the decrease of water volume $V_{w 1}$.

Water level in boiler drum may be searched out according to water volume changing from fig. 11.

As a result of calculation of the water level decrease at generator shutdown it was shown, that water level falls lower than protection system setting $(-150 \mathrm{~mm})$ for boilers concerned (Fig. 12).

Besides,time $\tau_{A}$ during which it is possible to support auxiliary load using boiler stored energy is estimated experimentally before ALSA implementation. Method of this time calculation is described below. Water-steam circuit is split into two subsystems: steam generating and superheating. Then time during which it is possible to generate $\tau_{g}$ and superheat required quantity of steam $\tau_{s}$ are estimated separately:

$$
\tau_{g}=\frac{A_{g}}{Q_{g}} ; \tau_{s}=\frac{A_{s}}{Q_{s}}
$$

where $A=\Delta \sum_{i=1}^{n}\left(m_{i} c_{i} T_{i}+V_{i} \rho_{i} h_{i}\right)$ - available stored energy, $Q_{g,}, Q_{s}$ - energy required for steam generation and superheating.

Time of stored energy utilizing is:

$$
\tau_{A}=\min \left(\tau_{g} ; \tau_{s}\right)
$$

For $670 \mathrm{t} / \mathrm{h}$ steam capacity boiler steam generating time is less than steam superheating time and they are equal to $\tau_{g}=17 \mathrm{~min} ; \tau_{s}=38 \mathrm{~min}$.

Distribution of stored energy on storing capacities is shown in fig.13a. On the one hand stored energy for steam generating $A_{g}$ is less than stored energy for steam superheating $A_{s}$. On the other hand it is required more energy per time unit for steam generating than for steam superheating. Besides, available water stored energy $A_{w}$ is less than steam stored energy $A_{s t}$.

The components of stored energy are shown in fig.13b. Whenboiler uses stored energy for auxiliary load support, drum water is not release energy but consume it, because this component of stored energy $A_{d}$ is negative. It occurs because of water density increase at pressure and temperature decrease. Water mass in boiler increases too, that's why it consumes stored energy. But if drum water volume is reduced at the emergency, water will consume less energy. And for $670 \mathrm{t} / \mathrm{h}$ steam capacity boiler energy consuming of water will be equal 0 if drum water level is lowered down to $-105 \mathrm{~mm}$. Then steam generating time will increases by $2.5 \mathrm{~min}$ :

$$
\tau_{g}=19,5 \mathrm{~min} \text {. }
$$

Thus, ALSA implementation on power-generating unit allows fast recovering of unit load after emergency. Applicationofcalculatingmethodsdecreasequantityofpreliminaryexperiments from 3-4 to one, which is acceptance test. Thereby costs of ALSA implementation are 3-4 times lower.

\subsection{Usage of matching balances method in the information-measuring system}

As the calculations show an increase of $1 \%$ operating efficiency of power unit owing to the operational control of the technical and economic indicators (TEI), the use of information computer systems (ICS) is effective (Ovchinnikov et al., 1977).

However, the definition of technical - economic indicators is possible only with a certain precision, which depends on the specific methodological errors of calculation algorithm, the errors of measurement equipment and measurement method. The rational algorithm for calculating the TEI allows significant reduction the impact of the first group of errors on the accuracy of the final result. But even if errors of this group is eliminated completely the actual error of TEI calculation in the working range of measurements and with usage manufactured instruments is in the range from 0.3 to $0.6 \%$ for an efficiency of steam generator and from 2.3 to $3.0 \%$ for the turbine performance and power unit (Tseytlin et al., 1975).

Economic efficiency of the ACS of technological process use on TPP is within a probability value of the TEI, therefore improving of accuracy of initial information for the ICS is extremely important.

Errors of TEI calculations when using the ICS can be reduced owing to individual elements calibration of the measuring channels (effective means for improving the measurements accuracy is calibration of individual elements or all measuring channel with help of a high-precision control equipment. Identified during calibration systematic errors can be further reduced in the operating range or taken into consideration when calculating the indicators. 
By means of individual calibration the error of generator power measuring channel may be reduced by more than $40 \%$ and steam rate may be reduced only by $15-20 \%$ due to the relatively high error of narrowing devices Total error of power unit and turbine parameters is reduced by $25 \%$ (Tseytlin et al., 1975)), stabilization of the external conditions (reduction of additional errors, which may even exceed the basic error of the instrument.

The main measures that reduce the additional errors are installing of the instruments in place with constant temperature and humidity, the stabilization of power supply, careful adjustment of input and output circuit resistance, elimination of vibrations, impact of magnetic fields and other activities as well as the selection of instruments for measuring the main technological parameters, which have the smallest additional errors.

As a result of external influencing factors stabilization total error of indicators can be reduced by $20 \%$ (Tseytlin et al., 1975), the optimal use of measuring tools and instruments of high accuracy. Together these measures can reduce the error of TEI up to $1.1 \%$ for power unit as a whole (Tseytlin et al., 1975).

Mentioned measures conform to main line of ICS development. Besides probabilistic and statistical method of information quality increase may be used as additional.

One of the important features of power unit operation in actual conditions is uncertainty of its real state at any point in time. The uncertainty has many reasons and main of them are following:

- some parameters don't change

- narrow measuring ranges of some parameters are comparable with error of control equipment

- $\quad$ numerical value of measured parameters are often estimated with significant measuring error

- time lag and fluctuation of parameters and process characteristic in power equipment of TPP cause object delay and increase divergence of material and energy balance

Thus probabilistic and statistical method of information quality increase complements the main methods for data accessing with minimal uncertainty.

\section{The Effect of Power Generating Equipment on Environment, Social Infrastructure and Health Care}

Nowadays ecological effect of TPP is urgent problem, which is social and connects directly with a sphere of human relationships. So, problems of emissions reduction and their effect on level of people's health are of great importance.

Pollutant emissions of TPP cover large area. This area is usually a city with developed social infrastructure and has dense population. Such emissions lead to quick ageing of buildings, constructions and other infrastructure objects. Besides, they cause population's health aggravation, which depends on surface concentration of harmful substances, and increase medical aid appealability. Both for infrastructure and population's health additional financing is required.

Comparative analysis of different Novosibirsk energy suppliers according to mentioned types of influence is shown in table 2.

Distributional pattern of emissions at a round wind rose from TPPs and boiler plants in Novosibirsk is shown in fig. 14 .

It is shown in (Shchinnikov, 2011) that optimal costs on health care should be $2.5 \ldots 3.5$ times higher than ecostructure costs irrespectively from power unit parameters and technological scheme of TPP. Given correlation is connected in the first place with presence of inhabitant and infrastructure, but only then with types of influence on them from some technological processes. If the higher quality of life is kept by developing and improvement of infrastructure, then the correlation in costs will change in favour of the last one.

Calculations of damages from different emissions sources on the functioning area of Novosibirsk TPP and boiler plants (table 2) were carried out. The calculation results show that this correlation is not hold even if main fuel is natural gas and emissions sources are situated from leeward side.

The last circumstance allows us to conclude that it is necessary to apply new approaches for defining of building area for energy suppliers nearby settlements.

\section{Conclusions}

Thus in the paper was given the following results of researches done by authors:

- Comprehensive researches of promising coal technology show that efficiency of such technology $1,15-1,7$ times higher than efficiency of conventional coal unit with steam parameters $12,8 \mathrm{MPa}$ and $540^{\circ} \mathrm{C} / 540^{\circ} \mathrm{C}$. 
- Researches of parameters deviation influences on fuel overexpenditure at unsteady provide exact cause-and-effect relation between automation means and fuel expenditure of TPP. It was shown, that fuel overexpenditure increases when load decreases.

- $\quad$ Researches of unit operation at emergency, when ALSA controls the unit, show that recovery time of unit normal load may be reduced thereby damage caused by emergency may be reduced significantly. The advices about ALSA implementation were given; thereby implementation costs may be reduced.

- $\quad$ Reasonable ratio between infrastructure and health care costs from TPP effect is 1:3 in big cities.

\section{References}

Dolezal, R. (1971). Simplified method of circulation calculation in steam generators. MiHeiluugender VGB (BDR) Ig., 51, vol. 3 .

Novikov, S. I. Novikova, L. V., \& Nikolskiy, N. V. (1981). Experience of implementation and maintenance of technological protection systems, that allow reduction the load on a power unit with coal-fired boiler. Express-Information: Energetics and electrofication. Maintenace and repair of power plant, vol.14, pp. 1-47.

Nozdrenko, G. V., \& Shchinnikov, P. A. (2009). Using the ORTES Computation System for Feasibility Studies of Thermal Power Stations.Science bulletin of NSTU, vol. 1 (19), pp. 51-62.

Ovchinnikov, U. V. Nozdrenko, G. V., \& Timashev, V. I. (1977). The increase of initial data accuracy in computer systems owing to matching balances method usage. Mode management and development of power grids with ACS, Novosibirsk. pp. 166-174.

Semenov, V. A. (2005). About emergencies in power grids abroad, Power engineering abroad. Russia, vol. 5.

Shchinnikov, P. A. Novikov, S. I., \& Dvortsevoi, A. I. (2009). An Exergetic Analysis of the Effect the Control Parameters of Coal Fired Cogeneration Units Have on Overexpenditure of Fuel. Science bulletin of NSTU, vol. 4, (37), pp. 163-169).

Shchinnikov, P. A. (2011). The effect of emissions of thermal power plant on its operating features. Bulletin of Russian Academy of Science: Energtics, vol. 6, pp. 133-142.

Tomilov, V. G. Pygach, U. L. Nozdrenko, G. V. Pygach, L. I. Ovchinnikov, U. V. Shchinnikov, P. A. Kapystin, V. A. Evtyshenko, E. A. Sazonov, I. N., \& Kochkin, S. S. (2000). Method of composite liquid fuel production. Patent for invention №2151959, 27.06.2000 (Russian Federation).

Tomilov, V. G. Pygach, U. L. Nozdrenko, G.V. Pygach, L. I. Ovchinnikov, U. V. Shchinnikov, P.A. Kapystin, V. A. Evtyshenko, E. A., \& Sazonov, I. N. (2000). Liquid coal fuel. Patent for invention №2151170. 20.06.2000. (Russian Federation)

Tseytlin, R. A. Stepanov, V. I., \& Shestov, E. D. (1975). About presicion of automated calculation of technical-economic indicators of power units. Heat and power engineering. vol. 1, pp. 8-13.

Table 1. The biggest blackouts

\begin{tabular}{|c|c|c|}
\hline Country & Blackout date & Time of disturbance, $\mathrm{h}$ \\
\hline USA & $1965 / 1977 / 1996 / 2003$ & $3 . .13 /$ up to $25 / 10 /$ up to 48 \\
\hline Austria-Bavaria & 1976 & 2 \\
\hline Italy & $1976 / 1978 / 2003$ & $0,5 / 0,6 / 5 . .20$ \\
\hline Canada & $1978 / 1982 / 1989$ & $4 . .10 / 5 /$ more than 9 \\
\hline France & 1978 & $2 . .8$ \\
\hline Sweden & $1979 / 1983$ & up to $4 / 24$ \\
\hline Great Britain & 2003 & 0,9 \\
\hline Russia (Moscow) & 2005 & 30 \\
\hline
\end{tabular}


Table 2. Wind rose influence on infrastructure and health care costs

\begin{tabular}{|c|c|c|c|c|}
\hline Emission source, MW & Burning fuel & Location & $Z_{\text {society }}, \mathrm{m}$. \$/year & $\begin{array}{c}Z_{\text {health, }} \\
\text { m. \$/year }\end{array}$ \\
\hline ТPР-320 & $\begin{array}{l}\text { Coal }-70 \% \\
\text { Oil }-30 \%\end{array}$ & Downtown & 3,0 & 65,0 \\
\hline ТРP -320 & Coal & Leeward side of the city & 1,86 & 17,2 \\
\hline ТРP -350 & $\begin{array}{l}\text { Coal }-70 \% \\
\text { Gas }-30 \%\end{array}$ & Leeward side of the city & 2,0 & 19,0 \\
\hline ТPР -480 & Gas & Downtown & 0,112 & 2,9 \\
\hline TPP -1000 & $\begin{array}{l}\text { Coal }-70 \% \\
\text { Gas }-30 \%\end{array}$ & Leeward side of the city & 5,0 & 36,0 \\
\hline TPP - 1000 & $\begin{array}{l}\text { Coal }-70 \% \\
\text { Oil }-10 \% \\
\text { Gas }-20 \%\end{array}$ & Leeward side of the city & 3,5 & 30,0 \\
\hline ТPP - 1000 & $\begin{array}{c}\text { Lignites }-70 \% \\
\text { Oil }-30 \%\end{array}$ & Leeward side of the city & 3,8 & 32,0 \\
\hline Boilerplant $Q_{\mathrm{T}}=300$ & Gas & Leeward side of the city & 0,002 & 0,011 \\
\hline Boilerplant $Q_{\mathrm{T}}=300$ & $\begin{array}{l}\text { Oil }-50 \% \\
\text { Gas }-50 \%\end{array}$ & Leeward side of the city & 0,003 & 0,272 \\
\hline Boilerplant $Q_{\mathrm{T}}=400$ & Gas & Leeward side of the city & 0,008 & 0,043 \\
\hline Boilerplant $Q_{\mathrm{T}}=600$ & $\begin{array}{l}\text { Oil }-50 \% \\
\text { Gas }-50 \%\end{array}$ & Leeward side of the city & 0,017 & 0,132 \\
\hline
\end{tabular}

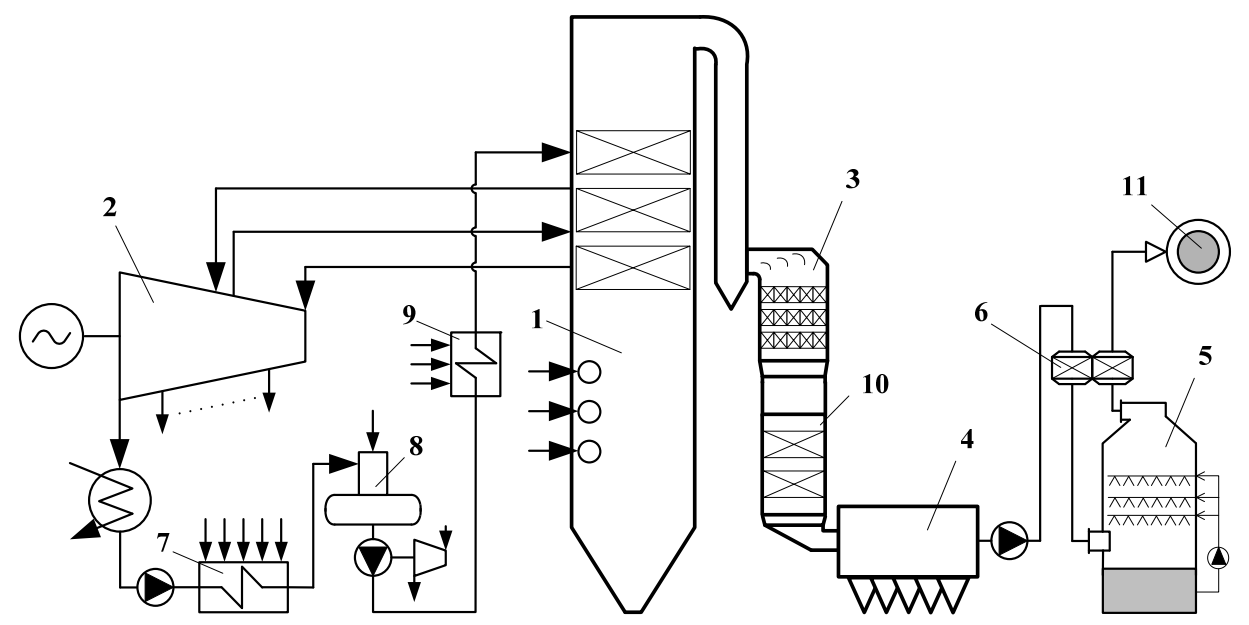

Figure 1. Schematic diagram of supercritical power unit with the systems of desulfurization and nitric-refinement: 1 - steam boiler, 2 - multi-cylinder turbine, 3 - reactor SCP, 4 - electrostatic precipitator, 5 -

absorber system desulfurization, 6 - gas heat exchanger (GHE), 7 - a group of low pressure heaters, 8 deaerator, 9 - a group of high pressure heaters, 10 - tubular air heater (TAH), 11 - exhaust into the atmosphere 


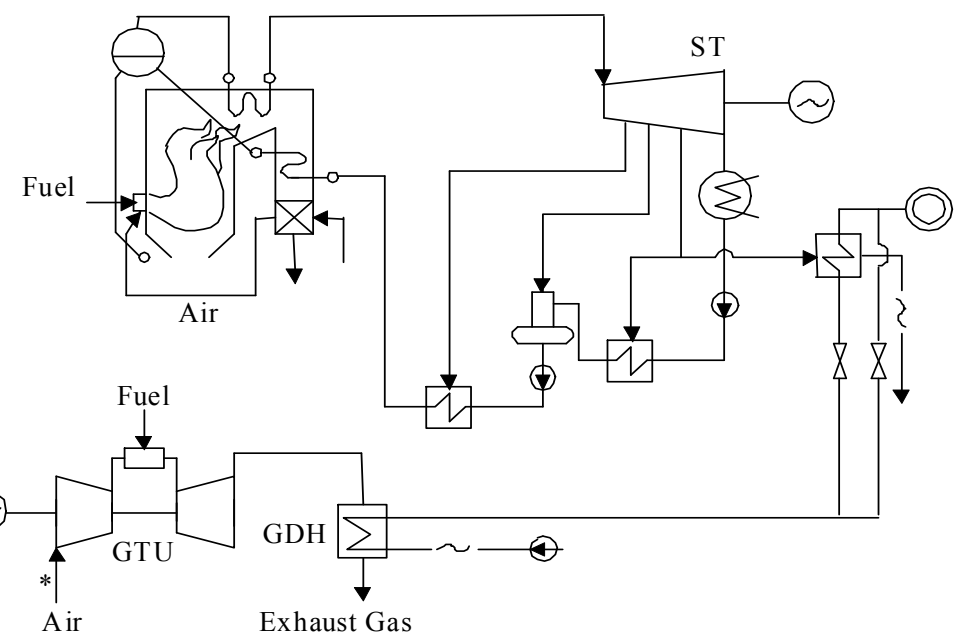

Figure 2. Schematic thermal diagram of heating combined- cycle power unit with gas delivery heater

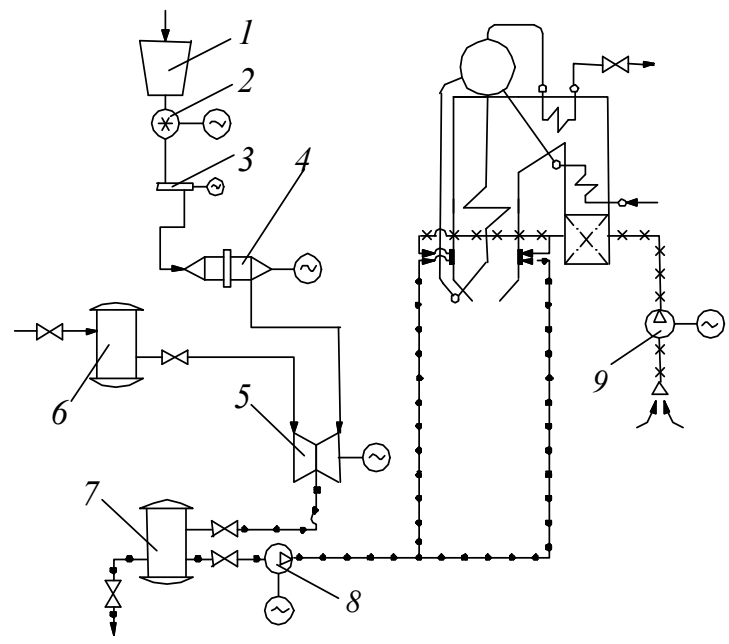

Figure 3. Schematic diagram of production and supply to the boiler cavitation composite liquid fuel: 1 - raw coal bunker, 2 - mill, 3 - feeder, 4 - disintegrator, 5 - cavitator, 6 - liquid tank, 7 - finished fuel tank, 8 - pump, 9 blow fan; technology provides molecular degradation of coal based on the cavitation effects

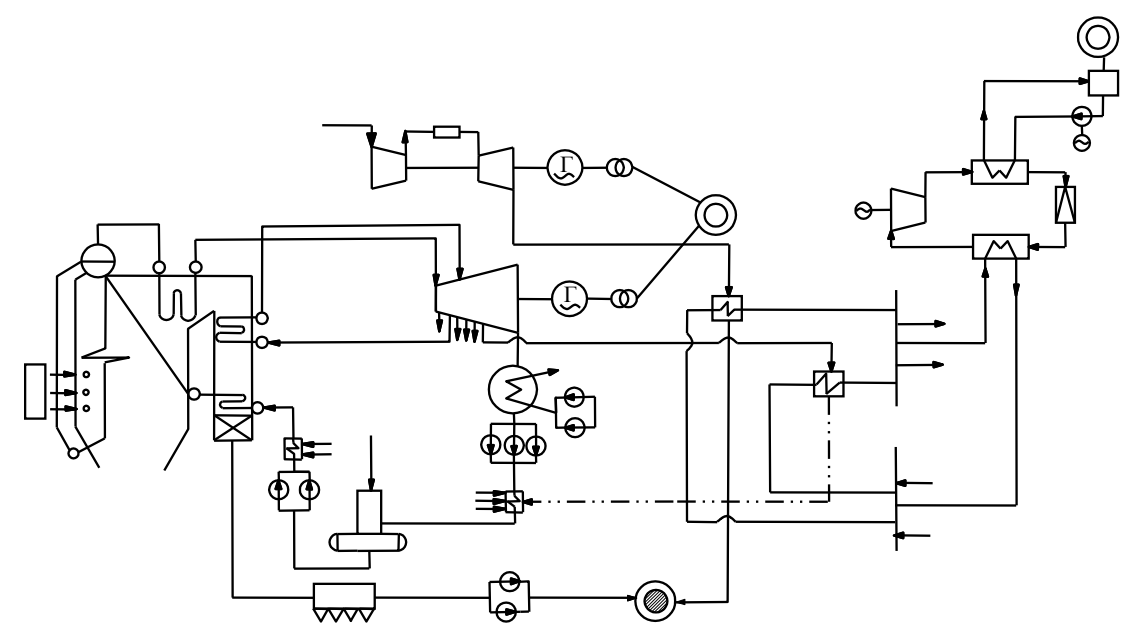

Figure 4. Technological diagram of combined heat power plant unit in the combined heat system with the gas delivery heaters and Freon compressor heat pumps 


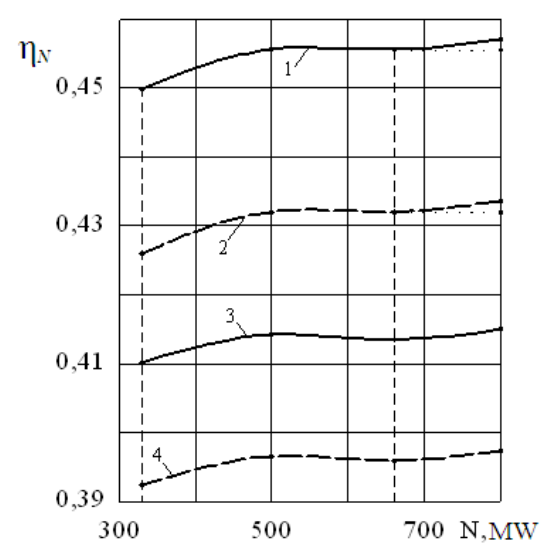

Figure 5. Efficiency supercritical parameters power units with the systems of desulfurization and nitric-refinement: 1,2 - gross and net efficiency of SCP power units; 3, 4- gross and net efficiency of supercritical pressure power units

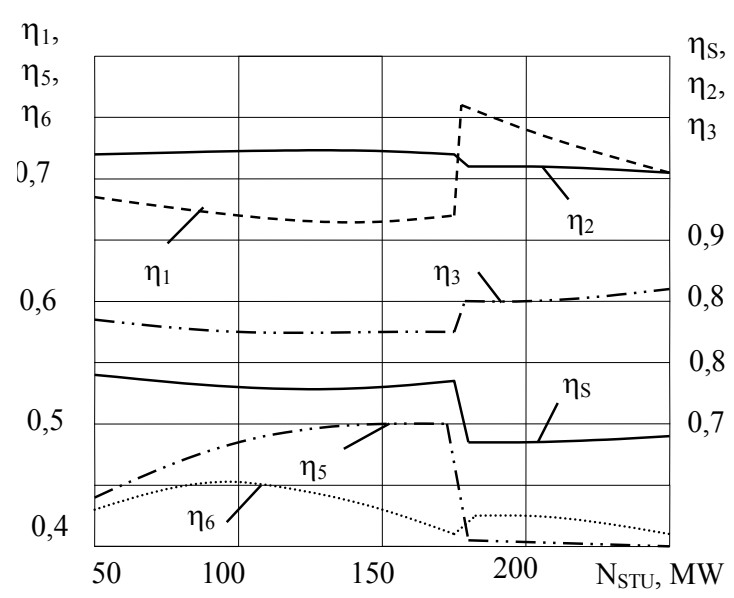

Figure 6. Optimum exergy indices of combined-cycle power unit with gas delivery heater in a combination of heat supply system with Freon termotransformers: $\eta_{1}, \eta_{2}, \eta_{3}, \eta_{5}, \eta_{6}$ - exergy efficiency subsystems: steam and gas generation, high pressure part of steam turbine, medium and low pressure part of steam turbine together with the gas turbine, regeneration and service water, delivery plant with GDH together main hot water systems and

Freon termotransformers; $\varepsilon_{\mathrm{S}}-$ structural exergy coefficient; $\mathrm{N}_{\mathrm{STU}}-$ capacity of steam turbine unit of combined-cycle plant

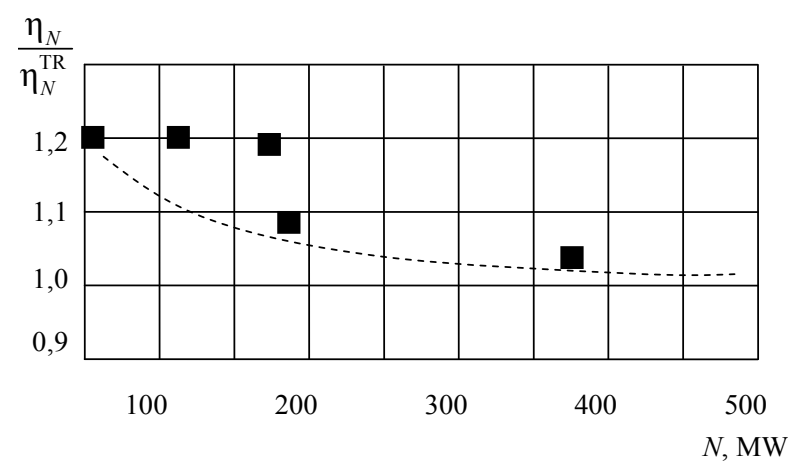

Figure 7. Relative exergy efficiency of power units with composite liquid coal fuel technology for electricity supply: $\eta_{\mathrm{N}}, \quad \eta_{N}^{\mathrm{TR}}$ - efficiency of electricity supply unit with composite liquid coal fuel and traditional with similar profile and unit capacity 


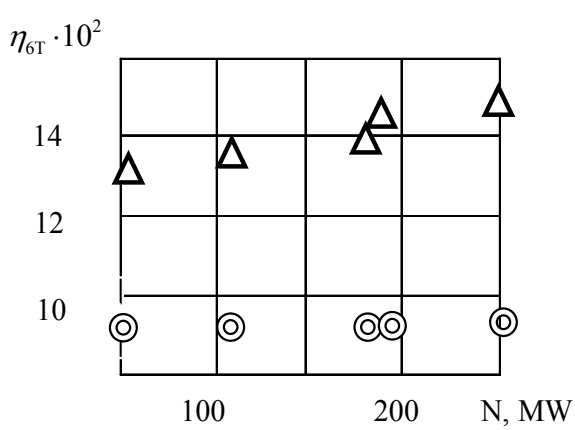

Figure 8. Exergy efficiency of heatexergy supply $\Delta$ - combined heat power plant with heat pumps for Freon R-134A;

๑- traditional steam turbine combined heat power plant

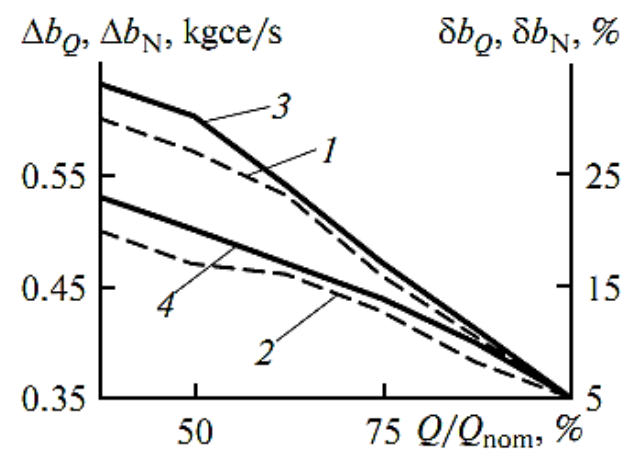

Figure 9. Overexpenditure of fuel for supply of heat and electricity due to deviation of live steam pressure $\Delta b_{Q}\left(p_{l . s}\right)$ and $\Delta b_{N}\left(p_{l . s}\right)$ and due to joint deviation of live steam temperature and pressure $\Delta b_{Q}\left(p_{l . s}, t_{l . s}\right)$ and $\Delta b_{N}\left(p_{l . s}\right.$, $t_{l . s}$ ) from their nominal values for the power unit constructed on the basis of a T-100 turbine

The abscissa axis is the ratio of the power unit's thermal power output to its nominal value. Deviations of live steam pressure: (1) $\Delta b_{Q}\left(p_{l . s}\right)$ and (2) $\Delta b_{N}\left(p_{l . s}\right)$. Deviations of live steam temperature and pressure: (3) $\Delta b_{Q}\left(p_{l . s}, t_{l . s}\right)$ and (4) $\Delta b_{N}\left(p_{l . s}, t_{l . s}\right)$. 


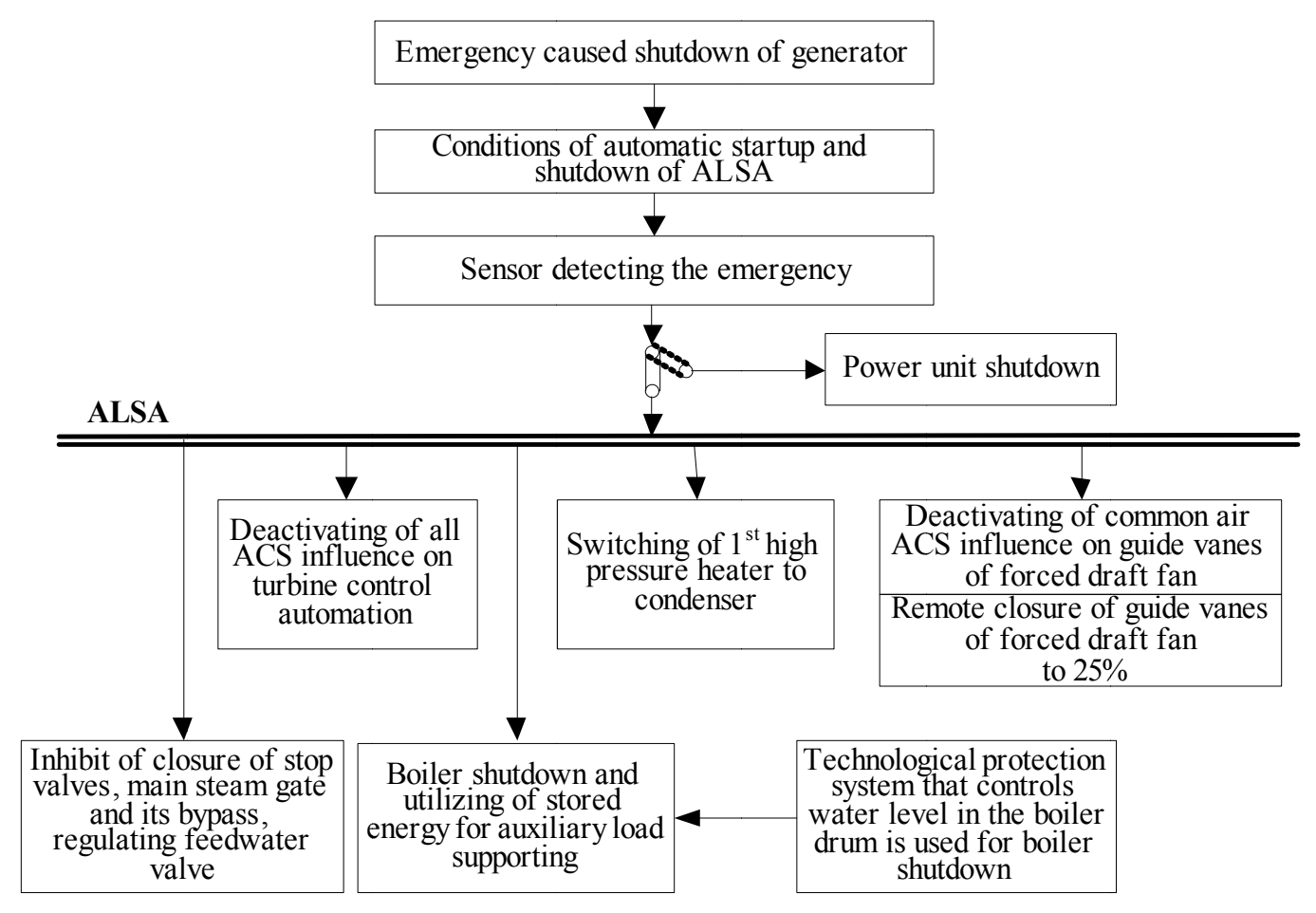

Figure 10. Algorithm of ALSA for a power unit with a drum coal-fired boiler

Water volume in boiler drum, $\mathrm{m}^{3}$

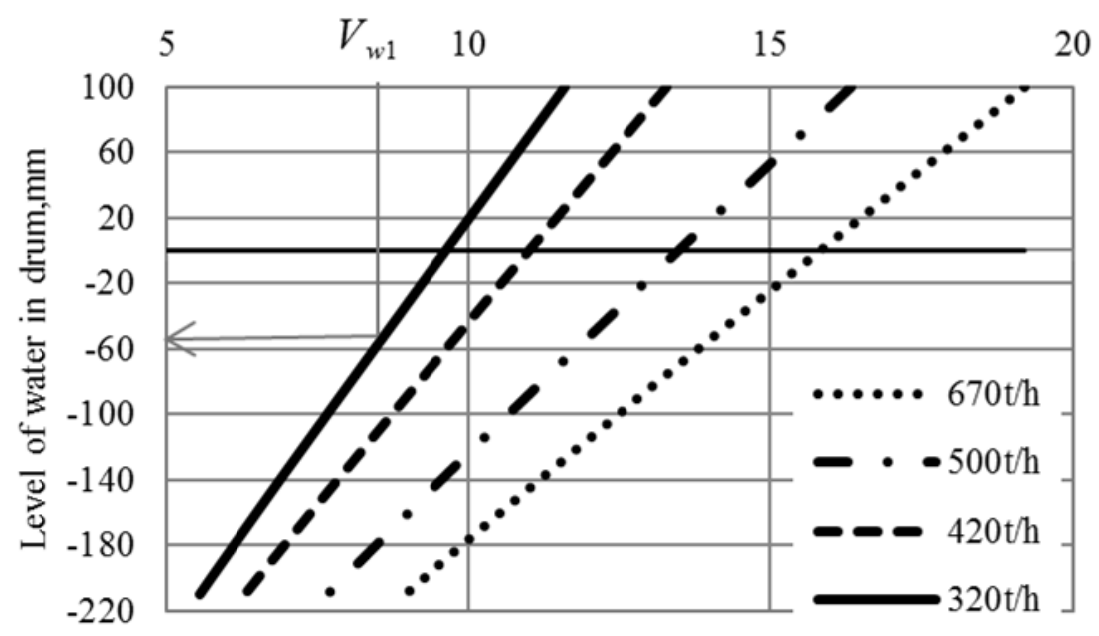

Figure 11. Dependence of water level in a boiler drum from water volume 


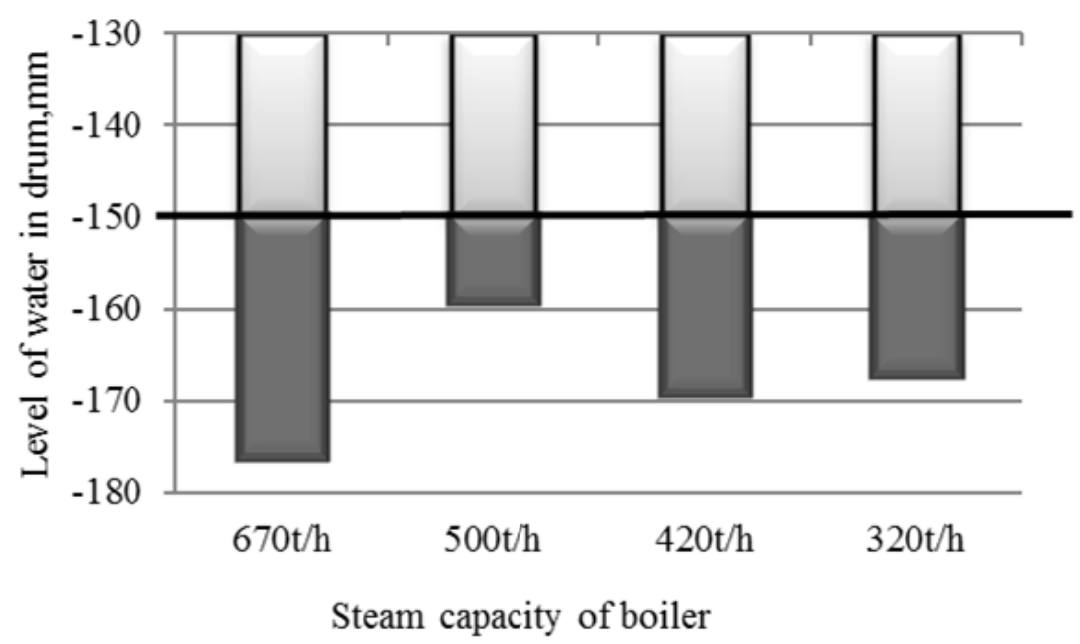

Figure 12. Water level falling in the boiler drum at generator shutdown
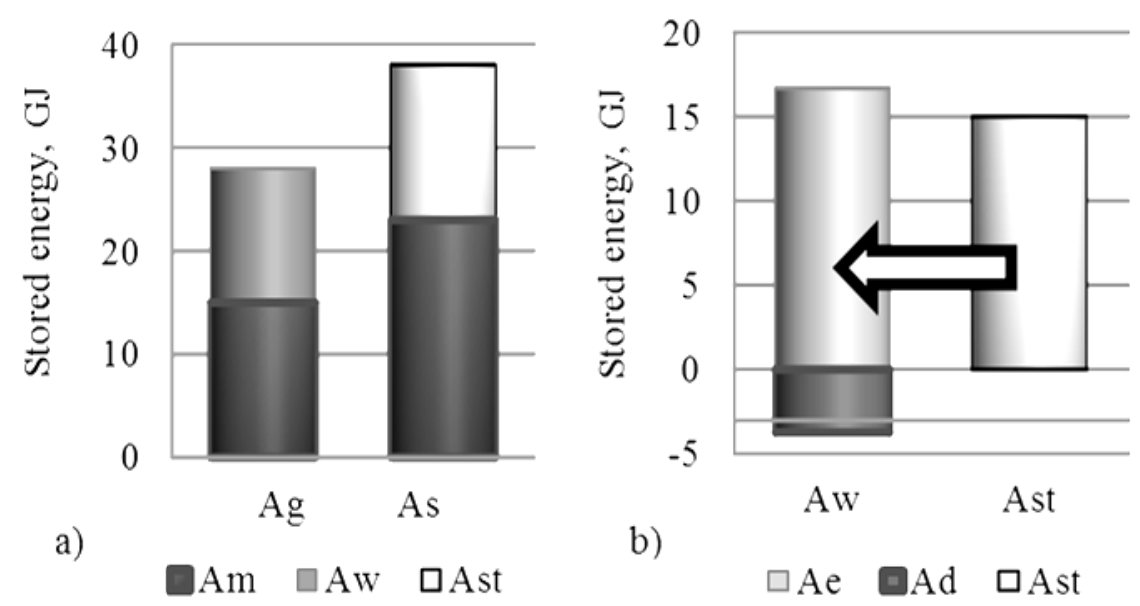

Figure 13. Distribution of stored energy on storing capacities

$A m$ - energy stored in metal construction of boiler, $A w$ - energy stored in boiler water, Ast - energy stored in boiler steam, $A e$ - energy stored in economizer water, $A d$ - energy stored in drum water, $A g$ - stored energy used for steam generation, $A s--$ stored energy used for steam superheating 


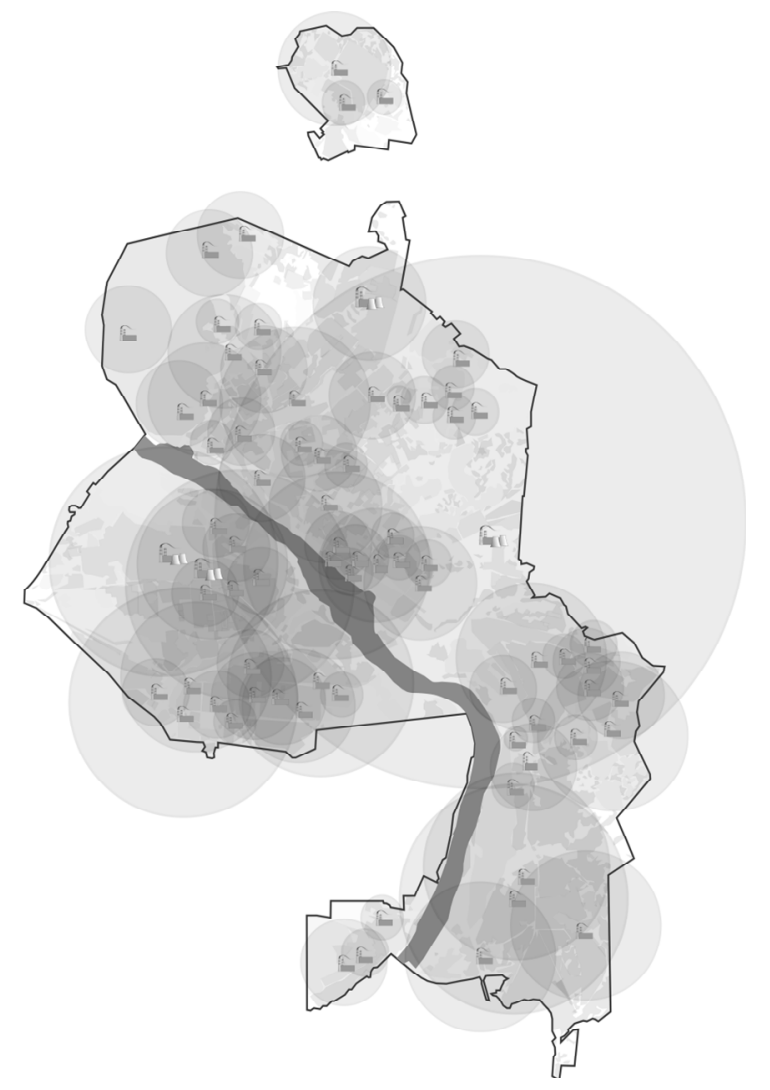

Figure 14. Emission distribution in the Novosibirsk atmosphere (The darker background is, the higher emissions intensity is) 